\title{
Utilização das unidades da paisagem para a prática do ecoturismo na Reserva Extrativista Marinha de Cururupu (MA)
}

\author{
Units of use of landscape for practice in ecotourism the \\ Marine Extractive Reserve in Cururupu (MA)
}

\author{
Francisco Wendell Dias Costa, Marivânia Leonor Sousa Furtado
}

\begin{abstract}
RESUMO
A criação e implementação de Unidades de Conservação tem se mostrado uma ferramenta que visa contribuir para a gestão ambiental do território, protegendo os patrimônios naturais, culturais e históricos. O Sistema Nacional de Unidades de Conservação instituído pela Lei no 9.985 de julho de 2000 , estabelece que as visitas nos moldes do turismo sejam permitas de acordo com o seu Plano de Manejo. Entretanto, nos últimos anos essa atividade tem causado impactos negativos às Unidades de Conservação, dessa forma, partiu-se para uma atividade que proporcionasse bem-estar ao visitante sem agredir o ambiente natural, assim a prática do ecoturismo ganhou destaque no cenário nacional. O objetivo deste trabalho é discutir sobre a utilização das unidades da paisagem para a prática do ecoturismo na Reserva Extrativista Marinha de Cururupu-MA. O trabalho está pautado na abordagem qualitativa e no método fenomenológico, bem como nos procedimentos metodológicos, tais como: levantamento e análise de material bibliográfico; trabalhos de campo e registro fotográfico. Os resultados evidenciam que a Reserva Extrativista Marinha de Cururupu criada em 2 de junho de 2004, abrange os municípios de Apicum-Açu, Bacuri, Cururupu, Porto Rico e Serrano do Maranhão, englobando 13 comunidades, onde residem aproximadamente 1500 famílias, tendo como principal atividade econômica a pesca artesanal. A explicação para o entendimento dos processos naturais e humanos deve ocorrer de maneira dinâmica e integrada, assim a abordagem geossistêmica é considerada a mais viável para o estudo da paisagem e sua potencialidade para o ecoturismo consiste em avaliar os elementos componentes dessa paisagem. Nesse contexto, buscou-se verificar as principais unidades da paisagem consideradas potencializadores da prática do ecoturismo na Resex de Cururupu, entre elas estão: os campos de dunas fixas e móveis, lagoas cristalinas, a exuberante formação dos mangues e a contemplação das aves migratórias, além dos aspectos histórico-culturais da Illha de Lençóis. Nesta, o ICMBio desenvolve um projeto denominado de Projeto de Ecoturismo de Base Comunitária na llha de Lençóis, sendo uma alternativa econômica aos moradores, cuja a caraterística primordial é desenvolver a prática ecoturística, potencializar atividades sustentáveis, assegurando o meio de vida e a cultura das populações ali existentes. Conclui-se que a prática do ecoturismo na Resex de Cururupu é vista como um importante fator de valorização econômica para as comunidades, mas ainda não se reflete como fonte extra de renda devido à falta de planejamento e gestão para a execução dessa atividade. Para potencializar a prática do ecoturismo na área de estudo é importante explorar as unidades da paisagem, configurando como instrumentos naturais capazes de atrair um grande percentual de turistas para a área. Com intuito de desenvolver o ecoturismo na Resex de Cururupu é importante também investir na implantação de uma infraestrutura adequada, investir na formação de guias (moradores das comunidades); promoção de cursos e treinamentos; conscientizando e sensibilizando os moradores locais e turistas no que se refere ao uso e manutenção dos recursos naturais da Resex de Cururupu.
\end{abstract}

PALAVRAS-CHAVE: Unidades da Paisagem; Reserva Extrativista Marinha de Cururupu; Ecoturismo. 


\section{ABSTRACT}

The creation and implementation of protected areas has proven to be a tool to contribute to the environmental management of the territory, protecting the natural, cultural and historical heritage. The National System of Protected Areas established by Law №. 9985 of July 2000 states that the visits in the tourism molds are permitas according to its Management Plan. However, in recent years this activity has caused negative impacts on protected areas thus broke for an activity that would provide welfare visitors without harming the natural environment, and ecotourism gained prominence on the national scene. The objective of this work is to discuss the use of landscape units for ecotourism in the Marine Extractive Reserve of Cururupu-MA. The work is founded on the qualitative approach and the phenomenological method as well as the methodological procedures, such as survey and analysis of bibliographical material; field work and photographic record. The results show that the Marine Extractive Reserve Cururupu established in June 2, 2004, covering the municipalities of Apicum-Acu, Bacuri, Cururupu, Porto Rico and Serrano Maranhão, encompassing 13 communities, home to about 1,500 families, with the main economic activity artisanal fisheries. The explanation for the understanding of natural and human processes must occur in a dynamic and integrated way, so geosystemic approach is considered the most viable for landscape study and its potential for ecotourism is to assess the elements of this landscape. In this context, we sought to identify the main landscape units considered boosters ecotourism practice in Resex of Cururupu, among them are: the fixed dune fields and furniture, crystal clear lagoons, lush mangrove training and contemplation of migratory birds, besides the historical and cultural aspects of Sheets Island. In this, ICMBio develops a project called Community Based Ecotourism Project in Sheets Island, being an economical alternative to residents whose primary feature is to develop ecotourism practice, enhance sustainable activities, ensuring the livelihood and culture of existing populations there. We conclude that the practice of ecotourism in Cururupu of Resex is seen as an important factor of economic recovery for communities, but still not reflected as an extra source of income due to lack of planning and management for the implementation of this activity. To encourage ecotourism in the study area is important to explore the landscape units, setting as natural instruments to attract a large percentage of tourists to the area. Seeking to develop ecotourism in Cururupu of Resex is also important to invest in the implementation of an adequate infrastructure, invest in training guides (community residents); promoting teaching and training; educating and sensitizing the locals and tourists with regard to the use and maintenance of natural resources Resex of Cururupu.

KEYWORDS: Landscape Unit; Marine Extractive Reserve Cururupu; Ecotourism.

\section{Introdução}

Em virtude do aumento da industrialização e da urbanização, ocorridos, sobretudo pós-segunda metade do século XX, profundas alterações foram verificadas no meio ambiente. Os problemas ambientais começaram a ser discutidos na procura por alternativas que atenuasse esses problemas e fossem capazes de preparar um futuro mais sustentável. Diante desse contexto, são criadas as Unidades de Conservação enquanto instrumentos territoriais legais capazes de salvaguardar o ambiente natural e históricocultural.

As Reservas Extrativistas como uma categoria de uso direto são capazes de envolver as populações tradicionais e fazer o uso racional dos 
recursos naturais, apresentando-se como um diferencial para a prática do ecoturismo, pois esses aspectos constituem seu principal atrativo.

A abordagem geossistêmica aplicada ao estudo da paisagem correlacionada a pratica ecoturismo consiste em estabelecer uma relação entre os processos naturais e humanos de maneira dinâmica e integrada, com possibilidades de identificação e análise do comportamento de alguns elementos da dinâmica das unidades da paisagem da Reserva Extrativista Marinha de Cururupu. Assim, as unidades da paisagem são elementos potenciadores para prática do ecoturismo na Resex de Cururupu (MA).

No dia 18 de julho de 2000, foi aprovada no Brasil a Lei no 9.985 que instituiu o Sistema Nacional de Unidades de Conservação da Natureza (SNUC), visando ordenar a gestão territorial por meio da criação e implementação de áreas protegidas. O documento sinaliza que alguns destes espaços podem e devem receber visitantes, isto é, o turismo é incentivado. Entretanto, há uma necessidade de se planejar a visitação para que possa cumprir os objetivos de cada Unidade de Conservação. Nesse sentido, o ideal é a prática do ecoturismo, que dentre seus objetivos visa a melhoria da qualidade de vida população envolvida nessa atividade.

O ecoturismo nas Unidades de Conservação pode ser uma forma de se atender aos princípios da sustentabilidade e da Educação Ambiental, pois representa um meio efetivo de atrair melhorias para a as localidades com grande potencial natural e sendo também um instrumento para a conservação ambiental.

A Reserva Extrativista Marinha de Cururupu possui uma área de aproximadamente $1.851,9332 \mathrm{~km}^{2}$, abrangendo os municípios de Apicum-Açu, Bacuri, Cururupu, Porto Rico e Serrano do Maranhão, apresentando diversas ilhas, baías, mangues, praia, manguezal. A principal atividade econômica da população que vive na Resex de Cururupu (MA) é pesca artesanal. É uma protegida por lei, integrando a Área de Proteção Ambiental das Reentrâncias Maranhenses, está incluída no Sítio Ramsar e no Pólo Turístico da Floresta dos Guarás. Sendo assim, deve apresentar um planejamento para a prática do ecoturismo na região.

Nesse contexto, o Instituto Chico Mendes de Conservação e Biodiversidade (ICMBio) desde 2011, desenvolve um projeto ecoturístico na Reserva Extrativista Marinha de Cururupu (MA), sendo intitulado de Projeto de Ecoturismo de Base Comunitária na Ilha de Lençóis, deve potencializar a prática dessa atividade, assegurando a conservação do recursos naturais e o meio de vida e a cultura das populações ali existentes.

A Reserva Extrativista Marinha de Cururupu (MA) possui uma grande riqueza natural, apresentando cordões de dunas fixas e dunas móveis, lagoas de água cristalina, inúmeras praias, os mangues, as aves migratórias, sendo consideradas unidades que formam uma exuberante paisagem natural, somado ainda com a riqueza histórico-cultural, sobretudo na Ilha dos Lençóis que agrupados passam a representar um grande pólo atrativo para o ecoturismo no Maranhão.

A Reserva Extrativista Marinha de Cururupu (MA) por ser uma Unidade Conservação de grande riqueza paisagística e histórico-cultural, sendo assim 
é uma área destinada à conservação ambiental, exercício da educação ambiental, pesquisa cientifica, contemplação da natureza e uso de forma sustentável dos recursos naturais pelas comunidades que ali vivem, também é destinada à prática do ecoturismo.

Partido desse contexto, o objetivo deste trabalho é discutir sobre a utilização das unidades da paisagem para a prática do ecoturismo na Reserva Extrativista Marinha de Cururupu (MA).

\section{Metodologia}

A metodologia utilizada neste trabalho foi desenvolvida com base na abordagem de estudos integrados sobre o ambiente natural, na qual busca 0 conhecimento e a avaliação dos componentes geoambientais dentro da concepção de geossistema. Apoiou-se também na abordagem qualitativa e no método fenomenológico, bem como procedimentos metodológicos.

Segundo Bertrand (1972) a classificação dos geossistema divide a paisagem em unidades menores, dessa forma o estudo da paisagem consiste em avaliar os elementos, quer seja natural ou antrópico, que a compõem. Nesse contexto, a abordagem proposta por Bertrand utilizada neste trabalho visa analisar a combinação dinâmica de elementos físicos ou naturais e socioculturais que são consideradas favoráveis para a prática do ecoturismo na Reserva extrativista Marinha de Cururupu-MA.

$\mathrm{Na}$ abordagem qualitativa procurou enfatizar a descrição dos fatos e elementos, envolvendo as crenças, valores, opiniões, dentre outras que são consideradas não quantificadas (MINAYO, 200). Dessa forma, subsidiou para a formação de um conhecimento obtido pela relação entre sujeito/pesquisador/sujeito a fim de criar elementos suficientes para reconhecer e compreender a dinâmica das unidades da paisagem como importantes para a prática do ecoturismo na área de estudo.

Para Lencioni (2003) a Fenomenologia constitui numa corrente filosófica que considera os objetos como fenômenos que devem ser analisados como aparecem na consciência do pesquisador. Com método Fenomenológico, o observador elabora os significados e interpretações dos fenômenos sociais descobrindo as características culturais que envolvem a existência das pessoas que participam da pesquisa, entendendo a realidade social como uma construção humana (TRIVIÑOS, 1987). Este método deu embasamento relativo à percepção pela sistematização dos processos de observação, interpretação e explicação dos fenômenos locais.

Sobre a observação como método de obtenção de dados e como um elemento na pesquisa científica permite o registro do comportamento das unidades da paisagem, cuja finalidade é verificar quanto essas unidades podem ser instrumentos potencializadores para prática do ecoturismo na Reserva Extrativista Marinha de Cururupu-MA.

Durante a etapa de investigação científica, a observação é inevitavelmente seletiva, pois é fruto de uma escolha ativa e não meramente por uma contemplação passiva de tudo que acontece ao redor. Nesse sentido 
os métodos científicos e a observação segue uma ordem, que partem, sobretudo dos procedimentos metodológicos (CALVANTI; VIDIANA, 2007).

- levantamento e análise de material bibliográfico e pesquisa documental em órgãos, tais como: Instituto Brasileiro de Geografia e Estatística (IBGE), Instituto Maranhense de Estudos Socioeconômicos (IMESC); Instituto Brasileiro de Meio Ambiente e Recursos Renováveis (IBAMA) e Instituto Chico Mendes de Conservação da Biodiversidade (ICMBio); pesquisa no site especializado em Unidades de Conservação ${ }^{1}$ para estabelecer proposições e estratégias para a análise da paisagem;

- trabalhos de campo entre os dias 04, 05 e 06 de junho de 2014 e 15,16 e 17 de setembro de 2014. Datas em que foram realizadas às reuniões do Conselho Deliberativo, cujo objetivo era discutir o trâmite do Plano de Manejo e as atividades de cooperação nas comunidades; nessa oportunidade foi possível visualizar através de registro fotográfico de algumas unidades da paisagem.

\section{Localização e caracterização da área de estudo}

A Reserva Extrativista Marinha de Cururupu (MA) ocupa uma área de aproximadamente $1.851,9332 \mathrm{~km}^{2}$, abrangendo os municípios de ApicumAçu, Bacuri, Cururupu, Porto Rico e Serrano do Maranhão, a 175 km em linha reta da cidade de São Luís, capital do Maranhão (Figura 1). Caracteriza-se pela presença de ilhas, baías, mangues, praias e elevada produtividade primária, contando com aproximadamente 30 ilhas habitadas ou não, apresentando significativa diversidade biológica, cultural, social e paisagística, despontando como área de beleza natural ímpar e grande potencial ecoturístico.

Integra a Mesorregião Norte Maranhense, a Microrregião do Litoral Ocidental e faz parte de um conjunto de instrumentos legais de proteção ambiente natural, histórico e cultural, sendo classificada como uma Área de Proteção Ambiental das Reentrâncias Maranhenses, estando incluída no Sítio Ramsar e no Pólo Turístico da Floresta dos Guarás.

Ocupa lugar estratégico no litoral ocidental do Maranhão, apontada por diversos estudos como a de maior densidade da biomassa litorânea, favorecendo uma concentração singular da biodiversidade marinha do Estado. A alta biodiversidade está concentrada nas florestas de manguezais, fundos lamosos e à salinada das águas, contribuindo para uma concentração de cardumes de peixes, crustáceos e mariscos. Essa riqueza de pescados potencializa a principal atividade econômica da população da área em estudo. 


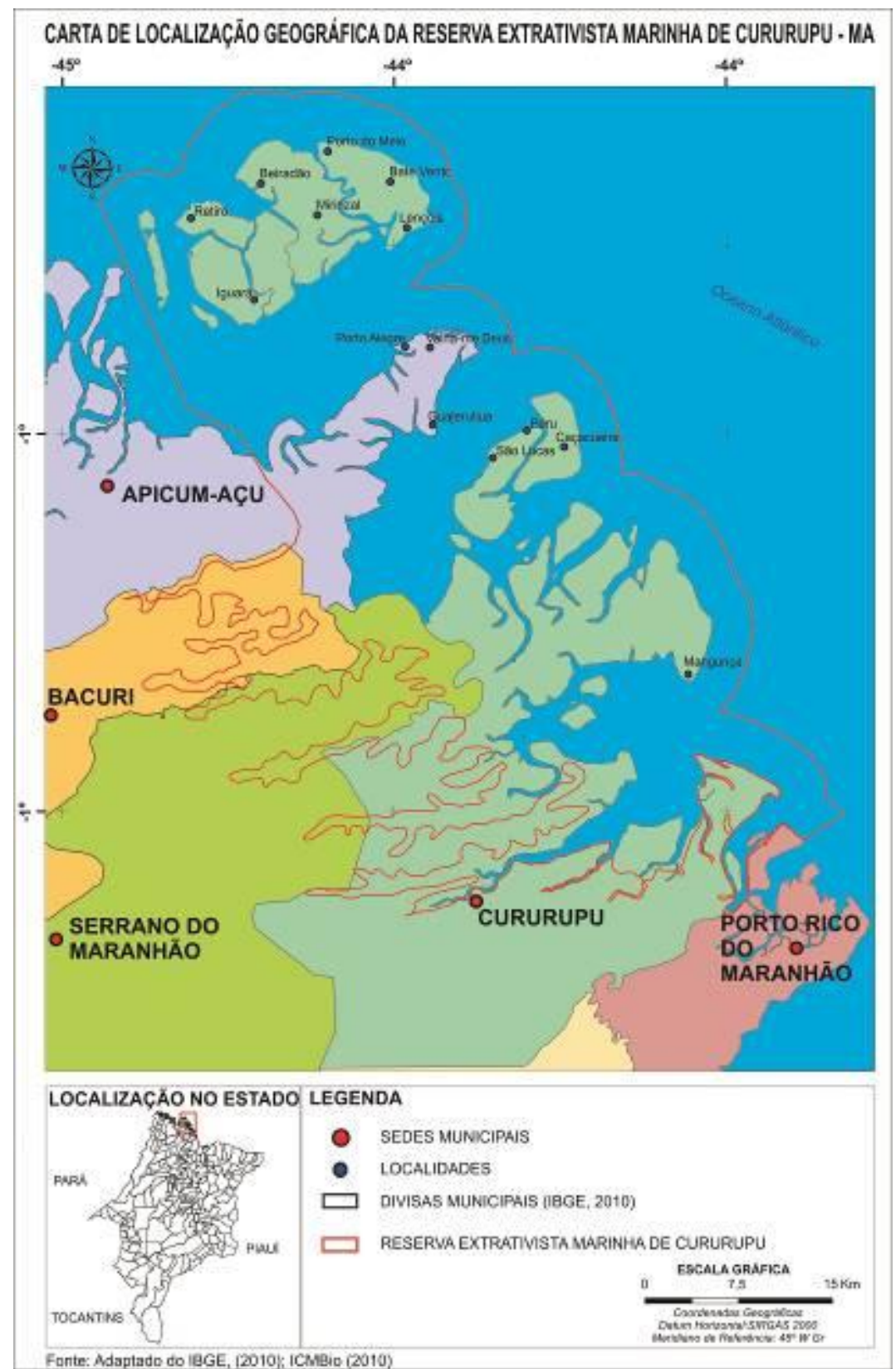

Figura 1: Localização da Reserva Extrativista Marinha de Cururupu.

Fonte: ICMBio (2010).

Figure 1: Location of the Extractive Marine Reserve Cururupu .

Source : ICMBio (2010).

A Resex Marinha de Cururupu (MA) possui 13 comunidades, (Mangunça, Caçacueira, Peru, São Lucas, Guajerutiua, Valha-me Deus, Porto Alegre, Iguará, Mirinzal, Retiro, Porto do Meio, Bate-Vento e Lençóis), com aproximadamente 1500 famílias e mais de 5 mil habitantes, que contam com escolas, postos de saúde e casas de força para geração de energia elétrica. As comunidades são assistidas pela administração pública da prefeitura de Cururupu, o que possibilita que as famílias permaneçam de forma integral nos locais (BARROS et al., 2002).

As atividades econômicas realizadas nas comunidades que pertencem à Resex em estudo concentram-se no setor primário da economia, com 
destaque para a pesca artesanal, agricultura de subsistência, extrativismo vegetal e pecuária extensiva. Sobre a pesca e a agricultura, a produção é destinada ao abastecimento familiar e o excedente é vendido para a compra de alimentos e utensílios domésticos (COSTA, 2009). Entretanto, não têm faltado críticas ao modelo de economia baseado no extrativismo vegetal, pois é uma atividade de baixa rentabilidade e é uma frágil base para o desenvolvimento, o que justifica também o nível de pobreza dos habitantes.

A exploração dos recursos pesqueiros é voltada para a subsistência da comunidade. Peixes, crustáceos e moluscos são capturados por meio de diversas artes de pescar de modo artesanal (tarrafa, espinhel, malhadeira, muruada, arrasto, zangaria, curral linha e anzol), com auxílio de embarcações pequenas do tipo canoa (casco) quando a prática ocorre até cerca de um quilômetro da costa, e bianas e embarcações grandes, motorizadas e à vela quando é feita nas baías ou em alto mar. Este último tipo de embarcação também faz o transporte de passageiros e de pequenas mercadorias. Os pescadores retornam de suas atividades trazendo vários tipos de pescados, crustáceos e moluscos entre outros, utilizados como fontes de alimento e de renda para muitas famílias da comunidade.

Apesar dos equipamentos existentes, a infraestrutura das comunidades é reduzida, algumas mais agravadas por conta da sua localização e difícil acesso. Alguns serviços públicos como água encanada, saneamento básico, transportes, coleta de lixo doméstico, dentre outros são inexistentes. A água consumida pelos moradores vem de poço domiciliar particular e/ou dos poços artesianos que são considerados públicos (COSTA, 2009).

\section{Abordagem geossistêmica e a dinâmica da paisagem}

$\mathrm{Na}$ Geografia, os estudos sobre a organização do espaço geográfico incluem as estruturas, os elementos e a dinâmica que ocorrem entre eles. Apoiada na teoria dos sistemas procurou-se explicar os processos naturais e humanos de maneira dinâmica e integrada, com possibilidades de identificação e análise do comportamento de alguns elementos da dinâmica das unidades da paisagem da Reserva Extrativista Marinha de Cururupu (MA).

A análise geossistêmica aplicada ao estudo da paisagem e sua potencialidade para o ecoturismo consiste em avaliar os elementos componentes do geossistema: a estrutura, o arranjo e a distribuição dos elementos, as características dimensionais, as relações entre os elementos, as características dimensionais, as relações entre elementos, os níveis de estabilização ou transformação, o grau de utilização e importância socioeconômica e o estado de interferência humana.

Os geógrafos russos e franceses denominaram essa visão como "Geossistema", sendo consagrada por Sotchava (1978). A utilização dessa abordagem nos estudos da Geografia Física possibilitou que o objeto de estudo tivesse um caráter interativo. Christofoletti (1999) indica que uma visão complexa sobre os sistemas ambientais físicos, torna-se compreensível sob a perspectiva da análise geográfica, haja vista que os processos e 
organizações dos elementos componentes tendem a englobar: estrutura, funcionamento e dinâmica dos elementos na organização do espaço.

Bertrand (1972) conceitua geossistema como um sistema aberto, hierarquicamente organizado, formado pela combinação dinâmica e dialética, portanto instável, de fatores físicos, biológicos e antrópicos. É a combinação dinâmica do potencial ecológico (geomorfologia, clima, hidrologia), da condição de exploração biológica natural (vegetação, solo, fauna) e de atividades antrópicas (Figura 2).

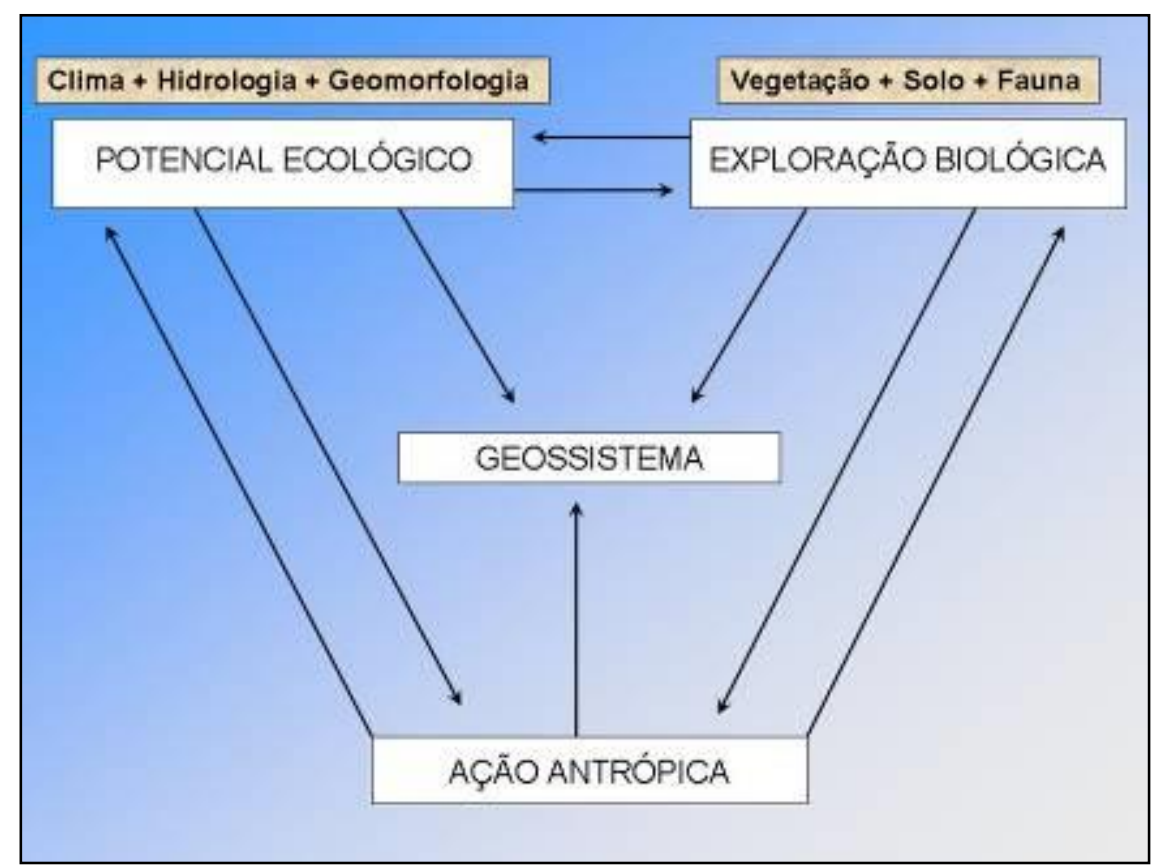

Figura 2: Esboço da definição teórica de geossistema, conforme Bertand (1972).

Fonte: Bertand (1972), adaptado por Costa (2009).

Figure 2 : Sketch of theoretical definition of geosystem as Bertrand (1972).

Source: Bertrand (1972), adapted by Costa (2009).

As abordagens da teoria geossistêmica adotada pela Geografia se encaixa perfeitamente nos estudos ambientais. Para melhor compreender a abordagem da dinâmica das unidades paisagem como elementos que contribuem para a prática do ecoturismo na Reserva Extrativista Marinha de Cururupu (MA), destacando a paisagem como uma categoria geográfica.

O vocábulo Paisagem pode indicar várias funções dependendo do contexto em que ele é utilizado. Souza (2007) assinala que pintores, arquitetos, geólogos, ecólogos e geógrafos possuem suas próprias interpretações, ganhando significado e definição ao projetar a contemplação de uma beleza cênica seja ela natural ou artificial de paisagem. Maximiano (2004) descreve que a Geografia alemã, de herança naturalista, destaca que a paisagem é um elemento meramente natural. Por outro lado, a escola francesa desenvolveu o conceito de uma paisagem formada pelas culturas e sociedades em cada espaço natural. 
A escola geográfica norte-americana considera que região e área são termos equivalentes à paisagem. Nessa visão, paisagem seria uma unidade da Geografia formada de associações e formas diversas sejam elas físicas ou culturais. O elemento cultural na paisagem é uma marca do homem, indicando que a cultura é um elemento que, agindo sobre o meio natural, resulta na paisagem cultural (MAXIMIANO, 2004).

Para Bertrand (1972) a paisagem representa uma determinada porção do espaço, resultante da combinação dinâmica e instável de elementos físicos, biológicos e antrópicos que reagindo de modo dialético formam um conjunto único e indissociável. Na Geografia a paisagem se constitui como um campo de investigação compreendido como um sistema ambiental no qual os elementos físicos, biogeográfico, sociais, culturais e econômicos se distribuem em estruturas funcionais complexas e organizações espaciais sistêmicas (CHRISTOFOLETTI, 1999).

A Geografia aborda a palavra paisagem sendo definida a partir da descrição da morfologia do ambiente, considerando os elementos naturais e humanos, perpetuando possibilidades sistêmicas, nas quais os trabalhos dos geógrafos buscam uma análise integrada da realidade, tendo como resultado a figura de uma paisagem repleta de elementos em constante interação e dinâmica.

Nesta pesquisa a concepção de paisagem considera um estudo sistêmico das unidades ambientais, privilegiando a articulação espaçotemporal da relação Natureza-Sociedade com propósito de relacioná-las como elementos para a prática do ecoturismo na Reserva Extrativista Marinha de Cururupu (MA).

\section{Unidades de Conservação e o ecoturismo}

O conjunto de Unidades de Conservação no Brasil foi agrupado em um sistema que após quase dez anos tramitando no Congresso Nacional, com várias emendas e modificações, até a assinatura da Lei no 9.985, de 18 de julho de 2000, instituindo o Sistema Nacional de Unidades de Conservação da Natureza (SNUC), sendo constituído por Unidades de Conservação federais, estaduais e municipais. A lei 9.985/2000, que institui o SNUC compilou leis e conceitos anteriores, definindo Unidade de Conservação como

espaço territorial e seus recursos ambientais, incluindo as águas jurisdicionais, com características naturais relevantes, legalmente instituído pelo Poder Público, com objetivos de conservação e limites definidos, sob regime especial de administração, ao qual se aplicam garantias adequadas de proteção (Art. $2^{\circ}$, BRASIL, 2000, p. 01).

Esse conceito definido pela lei tem claramente uma inspiração ambiental, que prevaleceu, em grande parte, sobre conceitos definidos pelo preservacionismo clássico ou tradicional. Pois há um valor intrínseco ao proteger a natureza por si mesma e não como reserva de recursos naturais para uso dos seres humanos. Por isso, o conceito de UC tem recebido 
diversas críticas porque não citou a importância das populações que ali vivem, deixando de lado os aspectos socioambientais na criação das Unidades de Conservação.

As Unidades de Conservação integrantes do SNUC dividem-se em dois grupos principais: Unidades de Proteção Integral e Unidades de Uso Sustentável. $O$ primeiro grupo tem como objetivo principal preservar a natureza admitindo o uso indireto dos seus recursos naturais, com exceção de casos previstos na Lei. Por outro lado, o segundo grupo visa compatibilizar a conservação da natureza com o uso sustentável de parcela dos seus recursos naturais.

As Unidades de Proteção Integral são: Estação Ecológica, Reserva Biológica, Parque Nacional, monumento Natural e Refúgio de Vida Silvestre. Já o grupo das Unidades de Uso Sustentável é composto por: Área de Proteção Ambiental (APA), Área de Relevante Interesse Ecológico (ARIE), Floresta Nacional, Reserva Extrativista (Resex), Reserva de Fauna, Reserva de Desenvolvimento Sustentável (RDS) e Reserva Particular do Patrimônio Natural (RPPN).

Essas Unidades de Conservação são áreas de domínio e acesso público. O Art. 4ํ do SNUC definiu os objetivos de cada unidade, que variam muito dependendo do tipo de unidade de conservação a qual ela pertence, dentre os objetivos está o XII que afirma que se deve favorecer condições e promover a educação e interpretação ambiental, a recreação em contato com a natureza e o turismo ecológico. Fica claro, que há uma relação entre as belezas naturais apresentadas pelas Unidades de Conservação e prática do ecoturismo que vem se desenvolvendo nos últimos anos.

Os ambientes naturais, tais como são as Unidades de Conservação, são considerados pelo turismo como recursos paisagísticos que aparecem como atividades de exploração e atratividade, sendo produtos de consumo. Entretanto, com a aplicação dos princípios da sustentabilidade no turismo torna-se um fator fundamental para o conhecimento, educação e conservação daqueles ambientes (KINKER, 2002).

O turismo é considerado uma atividade que visa proporcionar lazer, bem-estar e o descanso ao homem. Além do desenvolvimento dos transportes e do aumento dos salários, cria um novo modo de vida na sociedade moderna (QUEIROZ, 2006). Essa atividade tem um aspecto social tão importante quanto o desenvolvimento econômico, mas deve ser bem planejada e dentro dos princípios de sustentabilidade, pode evidenciar a importância histórico-cultural e ambiental das comunidades receptoras.

O turismo ecológico ou ecoturismo é aquele que consiste em viagens ambientalmente responsáveis com visitas a áreas naturais relativamente sem distúrbios, para aproveitar e apreciar o meio ambiente e as manifestações culturais, promovendo a conservação e contribuindo para o desenvolvimento socioeconômico das populações locais (CEBALLOS-LASCURAIN Apud PIRES, 1998). A Embratur (1994) classifica o ecoturismo como um segmento da atividade turística que utiliza, de forma sustentável, o patrimônio natural e cultural, incentiva sua conservação e busca a formação de uma consciência ambientalista através da interpretação do meio ambiente, promovendo o bemestar da populações envolvidas. 
A Lei Geral do Turismo no 11.771 , de 17 de setembro de 2008, dispõe sobre a Política Nacional de Turismo que discute a inclusão do turismo como fator de desenvolvimento local a partir de um planejamento ambiental, no qual visualiza as unidades de conservação como áreas promissoras para tal atividade (BRASIL, 2008).

Tal assertiva pode ser confirmada no parágrafo único do Art. 5 que quando se tratar de unidades de conservação, o turismo deverá ser desenvolvido em consonância com os objetos de criação e com o disposto no plano de manejo de cada unidade. Entretanto, sabe-se que a implementação dos planos de manejo nas UCs ainda é desafio a ser superado, o que pouco contribui para a prática do ecoturismo.

\section{Potencialidades do turismo no Maranhão}

O Brasil por apresentar grande extensão territorial abarca diferentes zonas climáticas, apresenta uma enorme diversidade de paisagens e ecossistemas. Dentre esses se encontra a Floresta Amazônica; o Pantanal, a Caatinga; o Cerrado; Matas de Araucárias, as florestas de altitude da Mata Atlântica e um vasto manguezal que acompanha todo o litoral brasileiro. Dessa forma, o Brasil se apresenta como um país de riquíssima biodiversidade, potencializando a prática do ecoturismo.

O Maranhão é um estado da Região Nordeste e devido sua grande extensão territorial é oitavo em extensão do Brasil, caracterizado por situar-se em uma área de transição entre o Cerrado, Floresta Equatorial e Caatinga, o que concorre para apresentar grande biodiversidade, além de possuir uma das maiores áreas de manguezais do país. Sendo assim, o Maranhão apresenta diversos atrativos naturais em forma de Unidades de Conservação com destaque para Chapadas das Mesas, o Parque Nacional dos Lençóis Maranhenses, o Delta das Américas, do Parcel de Manuel Luís, dentre outras.

O governo federal visando o crescimento dessa atividade nos estados, cujo objetivo era atrair investimentos complementares para as áreas com tal potencialidade, nesse caso inclui-se o Maranhão, desenvolveu programas, entre eles destacam-se o Programa de Desenvolvimento do Ecoturismo na Amazônia (PROECOTUR) e o Programa de Ações para o Desenvolvimento do turismo do Nordeste (PRODETUR). Esses dois programas também possuem ações voltadas para o Maranhão. Além desses dois programas o estado possui o Plano Maior.

O governo do Maranhão lançou em 2000, o Plano de Desenvolvimento Integral do Turismo do Maranhão, conhecido como Plano Maior que estabelecia até 2010 o desenvolvimento sustentável do turismo como forma atenuar a pobreza (MUNIZ; FERREIRA, 2014). As ações visavam a melhoria da qualidade de vida através da geração de emprego e renda para a população local. Tal discurso estava vinculado a uma diretriz federal assentada no Plano Nacional de Turismo (PNT), a qual específica que "o modelo de desenvolvimento proposto pelo governo contempla e harmoniza a força e o crescimento do mercado com a distribuição de renda e a redução das desigualdades" (BRASIL, 2013, p. 15). 
O Plano Maior de 2000 dividiu o Maranhão em cinco pólos, entre os quais a Floresta dos Guarás, dividido em 2009 em dois: Amazônia Maranhense e Floresta dos Guarás, abrangendo os municípios de ApicumAçu, Bacuri, Cedral, Cururupu, Guimarães, Mirinzal, Porto Rico do Maranhão e Serrano do Maranhão.

No Plano Maior de 2002, o Pólo Floresta dos Guarás, inserido na APA das Reentrâncias Maranhenses, foi classificada como uma região de grande potencial para o ecoturismo. Por outro lado, a atual versão do Plano Maior estabeleceu um período de 2010 a 2020, tendo como objetivo consolidar o Maranhão no setor turístico nos mercados nacional e internacional.

Esse novo plano, lançado em novembro de 2011, dividiu o estado em 10 (dez) pólos turísticos para que, no discurso, seja possível uma melhoria na qualidade de vida da população local a partir do crescimento econômico no fluxo de capital, de acordo com características próprias e atrativos comuns. São eles: São Luís; Munim; Parque dos Lençóis; Delta das Américas; Chapada das Mesas; Cocais; Serras Guajajara/Timbira/Kanela; Amazônia Maranhense; Floresta dos Guarás; e Pólo Lagos e Campos Floridos (MARANHÃO, 2011).

Segundo Maranhão (2008) os municípios do Pólo da Floresta dos Guarás fazem parte da Região de Planejamento do Litoral Ocidental e possuem como potencialidades a pesca, a cultura, a culinária, a agricultura, a construção naval, a pecuária, o extrativismo mineral, o turismo e o ecoturismo e como principais demandas: elaborar e executar programas de conservação ambiental, implementar políticas de inclusão social dos afrodescendentes, ampliar, restaurar e conservar a malha viária, qualificar mão-de-obra para a agricultura e a pesca, criar polo industrial, construir aterro sanitário, criar escola naval, conservar os manguezais (MUNIZ; FERREIRA, 2014).

Dentre os municípios em destaque da Região de Planejamento do Litoral Ocidental e conforme as duas etapas de campo desenvolvidas, destaca-se o município de Cururupu, por possui um extenso litoral, sendo caracterizado pela existência de ilhas, praias e extensas áreas de manguezais. Um dos principais atrativos do município é o Parcel de Manoel Luís, maior banco de corais da América Latina e o primeiro parque estadual marinho do país; destaca-se ainda a Reserva Extrativista Marinha de Cururupu, gerida pelo Instituto Chico Mendes de Conservação da Biodiversidade (ICMBio).

O município de Cururupu considerado a "porta de entrada" da Reserva Extrativista Marinha de Cururupu e do Pólo da Floresta dos Guarás é contemplado no Plano Maior com programas de saneamento básico, criação do centro de interpretação da natureza, melhoria de portos, da limpeza pública, da criação de áreas de interesse ecoturístico, da vigilância e fiscalização ambiental, do desenvolvimento de produtos de ecoturismo, de oficinas de treinamento ambiental, da criação de pousadas ecológicas, dentre outras que visam potencializar o ecoturismo na área (SANTOS; TEIXEIRA, 2009, p. 235-236).

A Reserva Extrativista Marinha de Cururupu (MA) possui um conjunto de exuberantes elementos naturais percebidos como unidades da paisagem, que estão em constante dinamicidade, potencializando a prática do ecoturismo. 


\section{Unidades da paisagem para a prática do ecoturismo na Reserva Extrativista Marinha de Cururupu (MA)}

Durante os trabalhos de campo foram identificadas algumas categorias das unidades de paisagens naturais e culturais que são utilizadas como práticas ecoturismo e demais atividades executadas pelos agentes sociais (extrativistas).

Por ser uma área costeira é comum aparecer entre os elementos que compõem a paisagem os campos dunas, que são resultantes do transporte e deposição dos sedimentos para as zonas emersas, que se acumulam formando as dunas. Em algumas comunidades as dunas são classificadas como dunas fixas, com predomínio de areias quartzosas de coloração embranquecidas, contendo feições com presença de vegetação típica que imobiliza ou reduz o transporte eólico dos sedimentos (Figura 3).

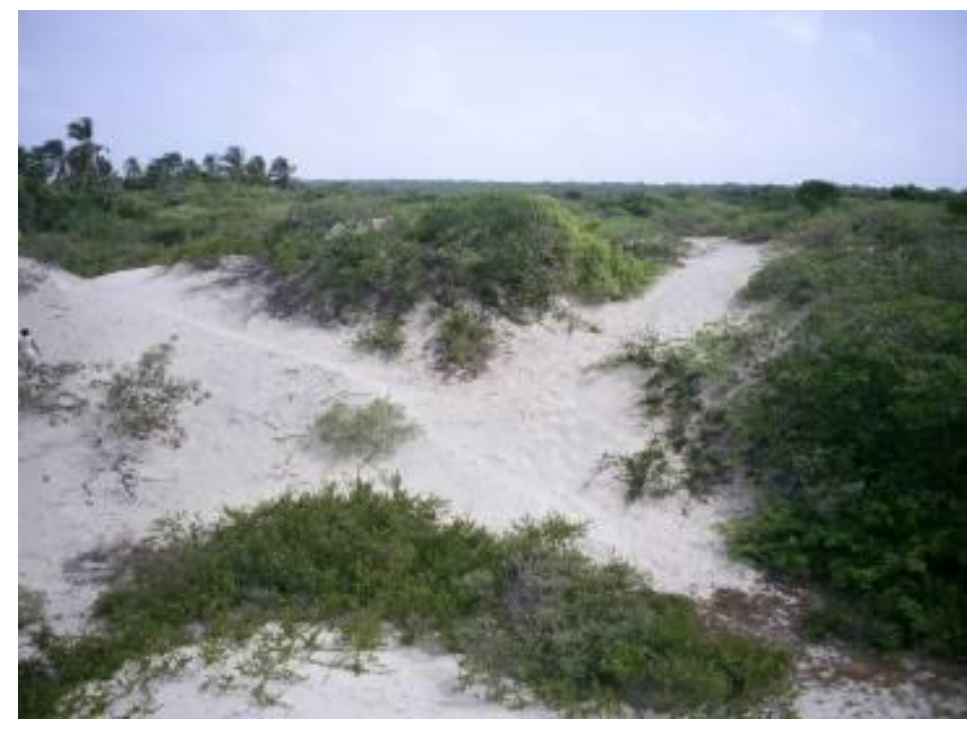

Figura 3: Cordões de dunas fixas na comunidade de Valha-me Deus.

Fonte: Registro da pesquisa.

Figure 3: Weld fixed dunes in the community of 'Valha-me Deus'.

Source: Research record.

Uma das principais atrações naturais da Reserva Extrativista Marinha de Cururupu (MA) é a llha de Lençóis, onde há uma exuberante paisagem formada por dunas móveis que se deslocam em razão do tamanho dos grãos, velocidade dos ventos e ausência de obstáculos, favorecendo o seu deslocamento. Em épocas chuvosas, formam-se lagoas de água cristalina entre as dunas, sendo frequentadas pelos ecoturistas, sobretudo nos meses de férias (Figuras 4 e 5). 
Figura 4: Dunas móveis na llha de Lençóis. Fonte: Registro da pesquisa. Figure 4: Shifting dunes in Lençóis Island. Source: Research Record.

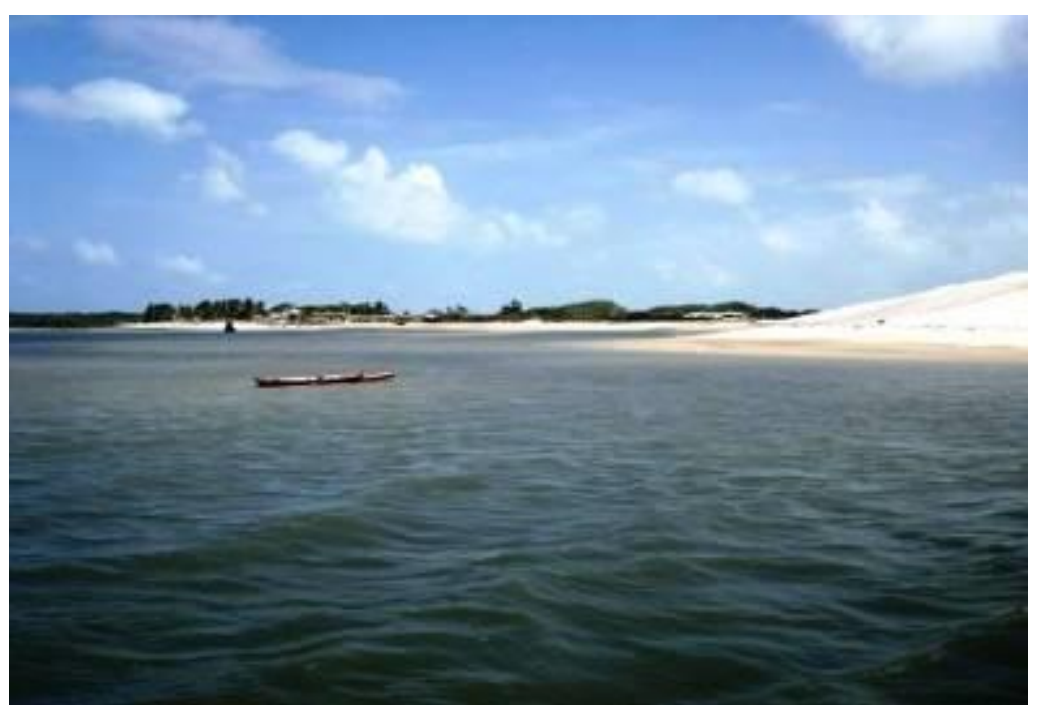

Figura 5: Lagoas que se formam no período chuvoso. Fonte: Registro da pesquisa.

Figure 5: Ponds that form during the rainy season. Source: Research Record.

Para Schaeffer-Novelli (1999), os mangues se desenvolvem no sistema ecológico costeiro, adaptado a um substrato periodicamente inundado pelas marés, com grandes variações de salinidade e com desenvolvimento de flora especializada. A importância do mangue está na proteção do equilíbrio socioambiental, pois a vegetação atua como estabilizadora do relevo praial, sendo um verdadeiro berçário de grande quantidade de espécies de peixes, crustáceos e moluscos marinhos, economicamente explorados pelas comunidades pesqueiras da Resex de Cururupu, para o consumo e para o mercado. Todas essas características potencializa a contemplação natural dessa formação vegetal, indicando um atrativo ecoturístico da Resex de Cururupu (Figura 6). 
Figura 6: O manguezal como atrativo ecoturístico. Fonte: Registro da pesquisa. Figure 6: The mangrove How attractive Ecotourism . Source: Record Search

O Instituto Chico Mendes de Conservação e Biodiversidade (ICMBio) desenvolve um projeto ecoturístico na Reserva Extrativista Marinha de Cururupu, sendo intitulado de Projeto de Ecoturismo de Base Comunitária na Ilha de Lençóis, desde 2011, sendo uma alternativa econômica aos moradores, cuja a caraterística primordial é desenvolver a prática ecoturística, potencializar atividades sustentáveis, assegurando o meio de vida e a cultura das populações ali existentes. Esse projeto tem parceria com a comunidade de Lençóis e tem sido de grande importância para a comunidade e para os turistas, através de ações voltadas à promoção de reuniões, cursos e parcerias para melhorar o atendimento turístico, além de servir de base para orientação e gestão do ecoturismo no local.

Alvite et al.(2015) afirmam que as pessoas que se deslocam até a llha de Lençóis, buscam maior contato com a natureza e com o convívio com moradores locais, a fim de completar as belezas naturais, caminhadas, banhos ao mar ou lagoas, além da observação da fauna e aves, além das experiências e aprendizado sobre a história e cultural da comunidade.

Diante desse contexto, surgem alguns problemas que são considerados responsáveis pelo afastamento dos turistas para a Resex de Cururupu, tais como: dificuldade de acesso e transporte até as comunidades, 0 abastecimento de água é feito por poços artesianos, falta de coleta adequada dos resíduos sólidos, não há rede coletora de esgoto, por essa razão a população utiliza fossas sépticas, em sua maioria, rudimentares, o que é agravado pelo fato de se localizarem próximas aos poços d'água, o que remete à possível contaminação dessa água, Não há rede de esgotos, embora haja um projeto de implantação, o que concorre para que os dejetos sejam lançados em cursos d'água ou em fossas sépticas.

Dessa forma, a implantação de um planejamento socioambiental somado com o Projeto de Ecoturismo de Base Comunitária na llha de Lençóis, pode potencializar a prática do ecoturismo na Reserva Extrativista Marinha de Cururupu.

\section{Considerações Finais}

As Unidades de Conservação por serem áreas de grande riqueza natural e histórico-cultural são tidas como um segmento para a prática do turismo, na 
categoria do ecoturismo, no qual deve ser de forma sustentável, valorizando e distribuindo de modo equitativo a riqueza gerada por essa atividade.

A prática do ecoturismo no município de Cururupu é vista como um importante fator de valorização econômica para as comunidades que pertencem a Reserva Extrativista Marinha de Cururupu, mas ainda não se reflete como fonte extra de renda devido à falta de planejamento e gestão para a execução dessa atividade.

Para potencializar a prática do ecoturismo na Reserva Extrativista Marinha de Cururupu é importante explorar as unidades da paisagem, configurando como instrumentos naturais capazes de atrair um grande percentual de turistas para a área. Entretanto, é importante também a participação dos diferentes sujeitos sociais no planejamento e monitoramento da atividade, possibilitando melhor a distribuição dos benefícios entre a população e levando a uma maior conservação e proteção ambiental.

O turismo, quando bem planejado, constituiu-se uma alternativa econômica capaz de gerar emprego e renda e contribuir para a proteção ambiental, como uma das possibilidades, é desenvolvido com o Projeto de Ecoturismo de Base Comunitária na llha de Lençóis desenvolvido pelo ICMBio. Nesse contexto, abre as portas para o ecoturismo em outras comunidades, mas para ser concretizado e implementado, faz-se necessário a aprovação pelos gestores da Resex de Cururupu.

Para expandir a prática do ecoturismo na Reserva Extrativista Marinha Cururupu é preciso inferir algumas considerações, tais como: investir na implantação de uma infraestrutura adequada, para que a relação atividade turística e conservação do ambiente seja desenvolvida de forma harmoniosa; desenvolver programas que insiram a participação da comunidade local nas atividades da Resex de Cururupu; investir na formação de guias (moradores locais), como é feito com algumas pessoas da llha de Lençóis, preparados para orientador e monitorar o fluxo turístico, ajudando na preservação do lugar.

Destacam-se também a promoção de cursos e treinamentos voltados para a preservação e manutenção do ambiente local e desenvolver campanhas educativas Educação Ambiental, conscientizando e sensibilizando os visitantes, moradores locais e turistas no que se refere ao uso e manutenção da natureza.

\section{Referências bibliográfica}

ALVITE, C.M.C. et al. Perfil da visitação na llha dos Lençóis, comunidade de pescadores tradicionais, Reserva Extrativista de Cururupu (MA). Revista Brasileira de Ecoturismo, São Paulo, v. 7, n.4 nov. 2014-jan. 2015, p. 656680.

BARROS, K. et al. (orgs.). Laudo biológico da Reserva Extrativista Marinha de Cururupu. São Luís: IBAMA, 2002.

BERTRAND, G. Paisagem e geografia física global. Esboço metodológico. Tradução de Olga Cruz. São Paulo: Instituto de Geografia, no 13, 1972. 


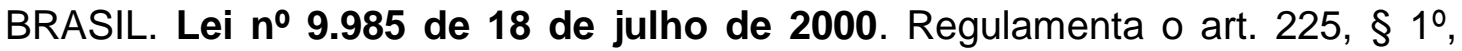
incisos I, II, III e VII da Constituição Federal, institui o Sistema Nacional de Unidades de Conservação da Natureza e dá outras providências. Disponível em: <http://www.planalto.gov.br/ccivil03/leis/6938.htm>. Acesso em: 29/03/2013.

BRASIL. Lei no 11.771 de 17 de Setembro de 2008. Dispõe sobre a Política Nacional de Turismo. Disponível em: <http://www.planalto.gov.br/ccivil 03/ ato2007-2010/2008/lei/l11771.htm>.

Acesso em: 30 de Março de 2015.

BRASIL. Ministério do Meio Ambiente. Planejamento para o sucesso da conservação. Brasília. Disponível em: <www.mma.gov.br>. Acesso em: 30 de março de 2015.

CAVALCANTI, A.; VIADANA, A.G. Organização do espaço e análise da paisagem. Rio Claro: UNESP-IGCE, 2007.

CHRISTOFOLETTI, A. Modelagem dos sistemas ambientais. São Paulo: Edgar Blücher, 1999.

COSTA, F.W.D. Dinâmica geoambiental da Praia de Valha-me Deus, Cururupu (MA). Monografia de Graduação em Geografia, Universidade Federal do Maranhão, 2009.

EMBRATUR. Manual de ecoturismo. DF: BSB, 1994.

LENCIONI, S. Região e geografia. São Paulo: EDUSP, 2003.

MARANHÃO. Secretaria Estadual do Turismo. Plano Maior - Maranhão 2020: "Turismo a certeza do futuro". São Luís: SETUR, 2011.

MARANHÃO. Secretaria de Estado do Planejamento. Regiões de planejamento do Estado do Maranhão, São Luís: SEPLAN, 2008.

MAXIMIANO, L.A. Considerações sobre o conceito de paisagem. Curitiba: UFPR, 2004. n. 8, p. 83-91.

MINAYO, M.C.S. et al. (org.). Pesquisa social: teoria, método e criatividade. 4 ed. Petrópolis: vozes, 2000.

MUNIZ, G.P.S.; FERREIRA, A.J.A. Turismo e uso do território no Pólo Floresta dos Guarás (2000 e 2011). Caderno de Pesquisa, São Luís, v. 20, n. 2, maioagosto de 2014.2 Disponível em: <http://www.pppg.ufma.br/cadernosdepesquisa/uploads/files/artigo-17(1).pdf>.

Acesso em: 30 de março de 2015.

MUNIZ, G.P.S.; FERREIRA, A.J.A. Turismo e qualidade e vida no município de Cedral-MA. Semana de Geografia: Território, Desenvolvimento e Patrimônio. Anais... São Luís: UFMA, 2012, p. 3.

PIRES, P.S. A dimensão conceitual do ecoturismo. Turismo - visão e Ação, v. 1, n. 1, 1998, p. 75.

QUEIROZ, O.T.M. Impactos das atividades turísticas em área de reservatório: uma avaliação socioambiental do uso e ocupação da Represa do Lobo, município de Itirapina/SP. São Carlos. Tese (Doutorado) - Escola de Engenharia de São Carlos, Universidade de São Paulo, 2000. 
SANTOS, S.R.; TEIXEIRA, M.G.C. Análise do plano de desenvolvimento turístico do estado do Maranhão: potencialidades e entraves na gestão de pólo turístico. Revista Turismo Visão e Ação, v. 11, n. 2. P. 218-241, 2009.

SCHAEFFER-NOVELLI, Y. Grupos de ecossistemas: manguezal, marisma e apicum. São Paulo, 1999.

SILVA et al. Ambientes de sedimentação costeira e processos morfodinâmicos atuantes na linha de costa. In: NETO, J.A.B.; PONZI, V.R.A.; SICHEL, S.E. Introdução à geologia marinha. Rio de Janeiro: Interciência, 2004. cap. 8, p. 175-218.

KINKER, S. Ecoturismo e conservação da natureza em parques nacionais. Capinas: Papirus, 2002.

SOTCHAVA, V.B. Por uma teoria da classificação dos geossistemas da vida terrestre. São Paulo: IGEOG-USP, 1977. no 14.

SOUSA, U.D.V. Dinâmica da paisagem da área do povoado de Ponta do Mangue, município de Barreirinhas-Maranhão. Monografia de Graduação em Geografia, Universidade Federal do Maranhão, 2007.

TRIVIÑOS, A.N.S. Introdução à pesquisa em ciências sociais: pesquisa qualitativa em educação. São Paulo: Atlas, 1987.

Francisco Wendell Dias Costa: Universidade Estadual do Maranhão, São Luís, MA, Brasil.

E-mail:wendeldis@ibest.com.br.

Link para o currículo Lattes: http://lattes.cnpq.br/6767224955990715

Marivânia Leonor Souza Furtado: Universidade Estadual do Maranhão, São Luís, MA, Brasil.

E-mail: marivaniafurtado@yahoo.com.br.

Link para o currículo Lattes: http://lattes.cnpq.br/3275591203804166

\section{Notas:}

${ }^{1}$ http://www.icmbio.gov.br/portal/biodiversidade/unidades-deconservacao/biomas-brasileiros.html.

Data de submissão: 28 de abril de 2015

Data de recebimento de correções: 17 de agosto de 2015

Data do aceite: 17 de agosto de 2015

Avaliado anonimamente 